\title{
A tensão entre fenomenologia e teoria nos comentários de Kant sobre a música
}

\author{
The tension between theory and phenomenology in Kant's \\ comments about music
}

\author{
Ricardo Nachmanowicz
}

ricnach@gmail.com

(Universidade Federal de Minas Gerais, Minas Gerais, Brasil)

\begin{abstract}
Resumo: Situados entre os parágrafos $\S 51$ e $\$ 53$ do que seria um adendo da Dedução dos juizos estéticos puros, estão os principais comentários de Kant acerca da arte musical. Esses comentários se inserem, por sua vez, em uma discussão maior sobre a divisão das belas artes e a caracterização individual de algumas artes. Procuramos demonstrar como Kant articula esses comentários musicais com elaborações teóricas pregressas, destacando criticamente os elementos fenomenológicos de sua descrição e os elementos teóricos que aplica para a compreensão do fenômeno musical.
\end{abstract}

Palavras-chave: música; E. Hanslick; epistemologia; estética; Kant.

\begin{abstract}
Situated between paragraphs $\S 51$ and $\S 53$ of what would be an addition of Deduction of Pure Aesthetic Judgments, we find the kantian main comments about the musical art. These comments are inserted in a broader discussion on the division of fine arts and the individual characterization of some arts. We seek to demonstrate how Kant articulates these musical comments with preceding theoretical elaborations, critically emphasizing the phenomenological elements of his description and the theoretical elements that apply to the understanding the musical phenomenon.
\end{abstract}

Keywords: music; E. Hanslick; epistemology; aesthetics; Kant.

\section{A música enquanto uma arte bela}

A recepção da Crítica da Faculdade do Juízo por parte dos especialistas em música não foi muito favorável, sobretudo pelo patente desmerecimento das qualidades musicais em relação às belas artes. Assim nos mostrou Mario Videira em seu artigo: “A recepção da crítica do juízo na literatura musical do início do século XIX"1. Amostras disso encontramos em Triest, ao se empenhar em incluir a música no conjunto das belas artes, ou em Michaelis, que chega a afirmar que a música, por ser mais afeita ao trabalho livre da imaginação, por estar desligada da imitação e

1 VIDEIRA, M. A recepção da crítica do juízo na literatura musical do início do séc. XIX. In: MARQUES, U. Kant e a música. São Paulo: Editora Barcarolla, 2010, pp. 181-209. 
da conceitualidade, é por isto a arte mais original e mais ideal de todas, buscando superar o sentido que Kant havia atribuído às belas artes².

Dado que os comentários empreendidos na terceira Crítica vêm sendo alvo de constantes críticas ou correções desde sua formulação, passaremos logo ao conjunto de avaliações mais drásticas, para em seguida voltarmos às razões do próprio Kant. A avaliação que recorremos é de Wheterston e ele assim avalia as especulações kantianas acerca do musical: "Sua análise se move inicialmente de uma análise transcendental para uma concepção de música que se torna cada vez mais pessoal e implausível"3.

A gravidade do comentário gira em torno da pessoalidade e mesmo de uma perda com o nexo da realidade que as especulações de Kant atingiriam. Essa opinião não é exclusiva de Wheterston e na verdade reflete, com pouca sutileza, a prevalência da opinião dos especialistas. Contudo, essa avaliação contrasta com o ponto de vista inicial de Kant: “O leitor não ajuizará este projeto de uma possível divisão das belas artes como teoria proposital. Trata-se apenas de uma das muitas tentativas que ainda se podem e devem empreender"4.

Certamente a hierarquização das artes fez aflorar os ânimos, uma vez que elabora e justifica um status para essas artes. Mas aquilo que parece ter gerado maior controvérsia no comentário kantiano foram certamente as descrições fenomenológicas musicais, quando não se correspondiam à experiência dos músicos e críticos musicais. Em segundo lugar, quando Kant não atribuía à música uma análise teórica que contemplasse as melhores faculdades em sua maior riqueza de atividades. A distinção entre as faculdades, assim como a distinção entre as artes, obedece a graus "inferiores" e "superiores", sendo as artes mais elevadas aquelas que compõem o seleto grupo das belas artes.

Há também certo arranjo cultural que ampara as preferências de Kant, que na verdade podem se mostrar bastante coletivas e menos pessoais do que Wheterston imaginava:

Pois em toda arte bela o essencial consiste na forma que convém à observação e ao ajuizamento e cujo prazer é ao mesmo tempo cultura e dispõe o espírito, para ideias, por conseguinte o torna receptivo a prazeres e entretenimento diversos; não consiste na matéria da sensação (no atrativo ou na comoção), disposta apenas para o gozo. ${ }^{5}$

Esse é o contexto geral onde se ilustram as características que fazem de uma arte uma arte bela. Portanto, para avaliarmos o que Kant tem em mente quando

\footnotetext{
2 Idem, 200.

3 WEATHERSTON, M. Kant Assessment of music in the critique of judgment. British jornal of Aesthetics, Oxford, Vol. 36, n. 1, 1996, p.63.

4 KANT, I. Crítica da faculdade do juízo. 2a edição. Rio de Janeiro: Forense Universitária, 1993, 204. 5 Idem, 171
} 
escreve seu comentário acerca da música, temos que entender que Kant faz parte e tenta justificar a conformação de uma cultura artística já formada.

Porém, nesse contexto pré-formado, dentre as artes que nos predispõem tanto ao entretenimento quanto para as ideias, a música simplesmente não faz parte, com algumas exceções: casos da poesia musicada, da ópera, do balé e do teatro musicado. Portanto, uma música poderia ser considerada uma arte bela apenas subsidiariamente, enquanto um suporte.

Mas, além de qualificar as belas artes, Kant também se dedica às artes individualmente. Ao investigar algumas artes individualmente, busca compreende-las a partir de suas capacidades em despertar ideias estéticas ou juízos estéticos puros, ou seja, o quanto cada uma, separadamente, guarda atributos das belas artes ou da beleza pura:

Aquela representação da faculdade da imaginação que dá muito a pensar, sem que contudo qualquer pensamento determinado, isto é, conceito, possa ser-lhe adequado, que consequentemente nenhuma linguagem alcança inteiramente nem pode tornar compreensível. ${ }^{6}$

Esse princípio concede à poesia a primeira posição. O que já é motivo mais do que suficiente para Michaelis reivindicar o mesmo princípio e a mesma colocação à música:

Nós nos perdemos na contemplação espiritual do elemento objetivo de uma bela composição musical, tanto quanto na sublimidade de uma ode de Klopstock; mas com a diferença que aqui [na ode] a nossa atividade é mais determinada, através de conceitos, enquanto lá [na música], a liberdade permanece, para acrescentar um conteúdo [Inhalt] para a mera forma da sensação. ${ }^{7}$

A argumentação de Michaelis procede, se quiséssemos interpretar o fenômeno musical enquanto mais disposto a juízos estéticos puros. Acontece que Kant não está considerando tão somente a correlação entre liberdade da imaginação e o desinteresse na materialidade (promovida por uma pretensa aconceitualidade musical). 0 componente essencial para Kant residiria na capacidade de uma arte sediar um máximo de produção de ideias estéticas:

a ideia estética é uma representação da faculdade da imaginação associada a um conceito dado, a qual se liga a uma tal multiplicidade de representações parciais, no uso livre das mesmas [...] portanto, permite pensar de um conceito muita coisa inexprimível. 8

Fica assim evidente que uma ideia estética se liga a um conceito e não apenas às

6 Idem, 192-193

7 MICHAELIS apud VIDEIRA, M. A recepção da critica do juízo na literatura musical do inicio do séc. XIX, 199.

8 KANT, I. Crítica da Faculdade do juízo, 197. 
sensações e à capacidade produtiva da imaginação. A arte bela é, portanto, aquela que guarda ainda certa aderência $a^{9}$ para que o juízo estético produza sociabilidade e cultura. Ou seja, a hierarquia das artes é ascendentemente marcada pela pertença de ideias estéticas, sociabilidade ${ }^{10}$ e aderência. Valores que, segundo Kant, a música possui em um menor grau.

Wheterston indica que Kant poderia estar na verdade preparando uma situação teórica, ligada à aderência, no intuito de ser possível incutir ou pelo menos pensar numa interação entre ideias estéticas e morais numa experiência sensível. Tal investigação excede nosso escopo, porém, pode ser uma boa explicação para a aderência estar ligada à produção das belas artes e elas terem um papel preponderante na filosofia de Kant.

Se conectarmos uma ideia estética a uma ideia da razão, a inexponibilidade [unboundedness] da ideia estética age como um símbolo para a indemonstrabilidade [unboundedness] de uma ideia da razão e, portanto, nossa capacidade racional é animada por este aspecto aparente do racional na experiência sensorial [\$49 (314$15)]^{11} \cdot{ }^{12}$

Não está explícito o modo como a ideia estética se apropria do entendimento a "dar o que pensar" sem que haja de fato um pensamento. 0 caráter inexponível e a propriedade da aderência que exige e "pressupõe um tal conceito e a perfeição do objeto segundo o mesmo" parecem mesmo incompatíveis ${ }^{13}$. Kant neste momento ampara-se mais na fenomenologia do que na teoria, e designa através do termo “ideias estéticas" e da expressão "dar o que pensar" um fato despertado por objetos de arte. O fato é relativo a um estado de livre imaginação onde conceitos e sensações se amontoam em uma só experiência. Mesmo que a teoria kantiana se utilize, por vezes, de expressões e conceitos não imediatamente atrelados a uma fenomenologia, é possível recolher alguma fenomenologia de base, que, de acordo com o filósofo, seria o fato que nos predispõe à sociabilidade e à promoção da cultura de modo geral, em ocasiões onde conceitos e sensações se conjugam e por isso moldam o contexto das belas artes.

Como podemos ver, a música instrumental do período clássico não poderia fornecer aderência à prática artística, tendo em vista que sua matéria não se comportava habitualmente nem como imagem nem como signo de outros objetos, e sua

\footnotetext{
9 Idem, \$16

10 Idem, $\$ 60$

11 WHETERSTON, M. Kant Assessment of music in the critique of judgment, 58.

120 autor usa originalmente o termo unboundedness para adjetivar tanto a ideia estética quanto uma ideia da razão. Ele parece querer apontar para o fato de ambas não possuírem limites precisos dentro de uma exigência regular do conhecimento. Porém mantemos a individualidade de cada adjetivação para situar o leitor habituado com a terminologia de Kant.
}

13 KANT, I. Crítica da Faculdade do juízo, 48. 
formalização também prescinde de tais conexões imitativas. Já no caso da pintura, ela consegue representar conceitos, mas também, os mover até suas determinações sensíveis ${ }^{14}$.

Analisemos então pormenorizadamente quais prejuízos a arte musical carregaria. O quesito sociabilidade é, segundo a avaliação de Kant, a maior fraqueza da música. A música parece conter a pior das indiscrições, sendo incapaz de se conter a um espaço só, perturbando assim a liberdade alheia e sendo avessa a um bom espírito de urbanidade. Contudo Rodrigo Duarte nos informa que Kant "suaviza" esta postura bastante "mal-humorada" na Antropologia15.

No quesito cultura, a música, diferente da pintura, seria incapaz de produzir uma “impressão permanente" 16 , sendo esta sempre transitória e impossibilitando o trato cultural sob um referente fixo. Kant, ao se referir à fenomenologia da percepção musical, acusa-a de não fornecer uma “impressão permanente”, e em deixar-nos sob um fluxo de baixos traços mnemônicos.

Para Kant, um caráter minimamente estável é essencial na promoção do jogo entre entendimento e sensibilidade que faça sobrar alguma aderência. Ou seja, o caráter estável de uma pintura permitiria um contexto mais educativo das faculdades, pois podemos nos fixar sobre ele ao longo do tempo de modo que ideias estéticas e sociabilidade podem estar assentes. Na música não haveria, digamos assim, uma consistência e fixidez inerente à sua forma de apresentação, impossibilitando uma ocasião artisticamente frutífera ${ }^{17}$.

É verdade que a música conta com uma transitoriedade inerente à sua composição e fruição. Porém, é duvidoso que tal aspecto da materialidade musical tenha interposto uma dificuldade prolongada em sua percepção, para qualquer tradição musical. É verdade também que músicos produziram diversas estratégias para conformar nossas capacidades cognitivas com a estruturação temporal, mas em todas as músicas significativas para as tradições populares e eruditas nota-se sempre padrões disseminados e reconhecíveis em que a atenção típica de cada época está bem representada nessas obras, longe portanto do esvaecimento descrito por Kant.

\section{Idem, 221}

15 DUARTE, R. A aconceptualidade da música em Kant e suas ressonâncias: Hegel e Adorno. In: MARQUES, U. Kant e a Música. São Paulo: Editora Barcarolla, 2010, p. 290.

16 KANT, I. Crítica da Faculdade do juízo, 221.

17 Dahlhaus compreende que houve um descompasso teórico que impossibilitava o século XVIII em perceber fenômenos temporais, tais como a música, como eventos consolidados em uma configuração determinante. Ao invés disso, e a expressão kantiana o demonstra, percebiam tão somente uma profusão transitória sem identidade. Cf. DUARTE, R. Belo, sublime e Kant. Belo Horizonte: Editora UFMG, 1998. Contudo, esse ponto de vista desconsidera todo o universo musical que lidava com obras musicais, terminologias e estratégias mnemônicas que faziam dessas obras objetos determinados como quaisquer outros, como demonstrado no livro Lógica e Música. NACHMANOWICZ, R. Lógica e música: conceitualidade musical a partir da filosofia de Kant e Hanslick. Belo Horizonte: Editora Relicário, 2014. 
Curiosamente, Kant também se interpõe ao recurso musical que produz padrões mnemônicos, considerando a repetição em uma obra musical, ou mesmo sua reprodução possibilitada pela fantasia, como um recurso que somente produziria sensações enfadonhas ${ }^{18}$. Vê-se aqui que nesse ponto a fenomenologia kantiana é bastante reduzida e isso interfere diretamente em suas conclusões teóricas.

Mas a característica mais marcante que confere à música um tratamento exclusivo por parte de Kant encontra-se no fato dela constituir uma expressão aconceitual. Aqui não seria lícito exigir de Kant uma interpretação diferente, visto que se convém nomear os constructos típicos da ação e função linguística como conceito ou como conceituais. Nesse sentido, certamente, a música não seria conceitual, pois não exerce função linguística. Contudo, Kant possui fundamento suficiente em sua primeira Crítica a lidar não apenas com conceitos puros e abstratos, mas também conceitos empíricos, e assim, o fenômeno musical poderia ser abordado de um ponto de vista que não o comparativo com a linguagem, mas também com os objetos empí$\operatorname{ricos}^{19}$. Contudo, afora essa possibilidade, e no contexto definido, sua fenomenologia pode ser considerada uma boa fenomenologia.

Assim, se assumisse que há conceitualidade na escuta musical Kant poderia abrir uma porta à possibilidade da música suscitar ideias estéticas e maior valor cultural, inclusive aderência. Porém, se a música configurasse uma atividade aconceitual, uma nova perspectiva se abriria, e foi esse o caso. Sendo um fenômeno meramente sensível, poderia despertar um juízo estético puro, como se sabe, um juízo onde sua finalidade é sem a consecução de um fim. Porém, Kant evita deliberadamente qualquer conjectura acerca dos juízos estéticos puros, evidenciando aqui uma fenomenologia que não busca seu correlato teórico imediatamente correspondente. Ao invés disso, e mantendo a música em um nível hierárquico inferior às demais artes, Kant confere enfim uma qualificação: "Também se pode computar como da mesma espécie [belezas livre] o que na música denominam-se fantasias (sem letra), e até a inteira música sem texto"20.

Kant credita à música uma beleza bastante específica e reservada a um grupo muito restrito de obras, ao lado de: folhagem para molduras, desenhos à la grecque e papel de parede ${ }^{21}$. A coleção dos trechos kantianos nos pode fazer crer que a beleza designada à arte musical será aquela que se distancia da forma matemática ou dos recursos mnemônicos racionalizados, como na forma sonata, e se aproxima dos

18 KANT, I. Crítica da faculdade do juízo, 221.

19 Sobre a exploração da característica conceitual do conhecimento presente na formação dos objetos empíricos aplicado à música, consultar: MARQUES, J. Harmonia e melodia na segunda analogia da experiência de Kant. In: MARQUES, U. Kant e a Música. São Paulo: Editora Barcarolla, 2010, pp. 129-141 e NACHMANOWICZ, R. Lógica e música: conceitualidade musical a partir da filosofia de Kant e Hanslick.

20 KANT, I. Crítica da faculdade do juízo, 49.

21 Idem, ibidem. 
arranjos musicais mais livres como a fantasia, tocata e a bagatela. Mas não enquanto formas específicas, e desde que indiquem uma atitude perceptiva que não seja focal e constitua-se mais difusa, mais ambiental. Novamente Kant conta com uma fenomenologia pouco elaborada, a distinguir nossa visada perceptiva dos padrões inerentes aos objetos, é pouco elaborada inclusive a compreender os padrões ornamentais que contam também com rigor formal, mas ainda assim, representativa dos hábitos estéticos de parte de sua cultura, e ainda hoje fortemente requisitados.

Inserir o papel de parede no hall das belas artes seria estranho a nosso senso comum, e provavelmente concordaríamos que o papel de parede ou o desenho à la grecque, depois de algumas observações, também produziriam enfado ${ }^{22}$. Nesse sentido, o ponto de vista kantiano é bastante coerente, e julga toda a classe das belezas livres da mesma forma. Fica claro também como o ponto de vista de Kant seria necessariamente polêmico a qualquer músico ou admirador desta arte. Podemos dizer que isso se deve em menor parte ao encadeamento de suas razões e principalmente pelo manejo de suas descrições fenomenológicas. Nos termos definidos por Kant, tanto para a arte bela quanto para a música, é acertada a conclusão de Kant quanto à música não ser uma arte bela, porém é inusitado que não tenha cogitado para ela um juízo estético puro. Mas e a caracterização da música enquanto uma beleza livre, porque Kant a qualifica desse modo?

Por beleza livre Kant compreende atividades que se encontram sob domínio das sensações e hegemonicamente representadas pela faculdade da sensibilidade. Em vista de sua natureza sensível, seus fenômenos típicos tenderiam mais a juízos de puro deleite, ligados à sensação corporal, dispensando ajuizamento intelectual ${ }^{23}$. O ponto máximo de formalização estaria na configuração do afeto que Kant, junto à tradição, admite às formas musicais, não enquanto conteúdo desses sentimentos, apenas enquanto o seu esquema. A posição de Kant se assemelha à de Rousseau, porém, diferente desse, não imputa à música a execução de afetos reais, mas tão somente uma forma não determinada de um afeto, seu esquema puro. Assim, um desligamento entre a intelecção e o afeto, e um desligamento entre o afeto e seu esquema, no interior da sensação musical, marca a compreensão kantiana do livre jogo para a música.

Os jogos livres da sensação são divididos em três: jogo de sorte, jogo de sons e jogo de pensamento ${ }^{24}$. 0 jogo dos sons é assim definido: “exige simplesmente a alternância das sensações, cada uma das quais tem sua relação com o afeto, mas sem

22 Interessante notar que Eduard Hanslick, considerando a música na mais alta cota artística, relaciona-a com arabescos e com o caleidoscópio, sem com isto indicar qualquer experiência de enfado, muito pelo contrário, sugere que essas formas são capazes de produzir ideias autônomas e ricas. Cf. HANSLICK, E. Do belo musical. Lisboa: Edições 70, 2002.

23 Idem, 222

24 Idem, 223 
o grau de um afeto, e desperta ideias estéticas"25.

Kant marca uma pequena diferença com as teorias tradicionais dos afetos ao afirmar que a música evoca um afeto apenas em sua “forma vazia”, porém, capaz de mover nossa imaginação e entendimento. Aqui, curiosamente, Kant concede a possibilidade de uma ideia estética para a música, sem conceder nenhum tipo de aderência, pois substitui a realidade do afeto por sua forma pura.

Resumindo o tópico, podemos dizer que Kant reserva para a música o juízo estético da beleza livre, devido ao fato da fenomenologia desse fenômeno se ligar fortemente a sensações corpóreas, e apenas brevemente a entrar em um livre jogo a partir dos esquemas dos afetos, mas que é rapidamente recomposto à sensação corporal amplificando- $\mathrm{a}^{26}$.

\section{A questão matemático-musical}

Vicente de Paulo Justi, ao abordar o comentário kantiano sobre música e matemática, faz referência a Giordanetti. Assim, faremos um comentário que aborde a posição de ambos:

Sobre este problema, Giordanetti afirma: Não se sabe, se realmente Kant assumiu a teoria de Euler. Ele também não sabe. [2005, p. 199]. Esta é a maneira de raciocinar de Kant, que Giordanetti explicita. Kant parece não desejar saber se Euler tem razão, mas se tiver a música será bela. ${ }^{27}$

Diferente do que tentam imprimir Justi e Giordanetti, mostraremos que a questão matemática não emerge como um quesito importante ou decisivo na caracterização da beleza musical empregada por Kant.

A questão matemática, que se liga intimamente ao trabalho científico de Euler, versa sobre a percepção dos sons. Kant se pergunta sobre o som [ton] aplicado à construção musical, e sua classificação enquanto frequência regular [pitch]. Estes são aspectos recém desvendados pela física de então, os quais Kant quer mostrar-se atualizado. Sem grandes interpretações, qualifica a frequência [pitch] enquanto qualidade pura, em contraposição à quantidade. Essa posição de Kant já destoa do próprio Euler, que havia proposto a tipificação do timbre enquanto "qualidade de individuação" dos instrumentos ${ }^{28}$ e da frequência enquanto a quantidade da nota em meio a um complexo de frequências. Como podemos ver, Kant se utiliza do expediente acústico a justificar a aconceitualidade musical já em sua composição física,

\section{Idem, 224}

26 Idem, 225

27 JUSTI, V. A música agradável, bela e sublime na terceira Crítica de Kant. In: MARQUES, U. Kant e a música. São Paulo: Editora Barcarolla, 2010, p. 100.

28 VELÁZQUEZ, D.; LONNGI, P. Contribuiciones de Leonhard Euler a la acústica. Miscelânea Matemática: Sociedad Matemática Mexicana, San Andrés Totoltepec, n. 46, Mayo/2008, p. 13. 
deslegitimando qualquer pretensão da categoria da quantidade.

Euler compartilhava de uma herança, própria da divisão das ciências, que incluía a música no interior de uma disciplina acústica, e esta, em uma disciplina matemática que formava o quadrivium. Dentro desta tradição, Euler cria uma correspondência entre o ajuizamento estético musical e as relações sonoras acústicas, baseado em relações matemáticas. Euler está construindo as bases da psicoacústica musical, cunhando os conceitos de consonância e dissonância e relacionando o gosto a critérios matemático-acústicos. Contudo, Euler não usa o termo "belo" em suas descrições:

Então Euler explicou como, a partir da ideia pitagórica, se pode estabelecer um esquema que mostre as regras de combinação harmônica das notas musicais e das que são agradáveis ao ouvido [...] as consonâncias se encontram em proporções mais simples e preferíveis ao entendimento, enquanto que as dissonâncias correspondem a proporções mais complicadas e por tanto são mais difíceis de compreender. ${ }^{29}$

Estes conceitos que vinculam o prazer e gozo musical à consonância foram sendo paulatinamente abandonados até o século XX. Embora tal concepção seja muito forte no século XVIII e XIX, Kant neste aspecto parece seguir um caminho mais interessante, corroborando em parte a crítica de Rousseau: “A melodia constitui exatamente, na música, o que o desenho representa na pintura - assinala traços e figuras nos quais os acordes e os sons não passam de cores [...] o império que a música possui sobre a nossa alma não é obra dos sons" ${ }^{30}$.

Rousseau vai incluir a música, por motivos singulares à sua tese, na lista das belas artes, inclusive, enquanto obra imitativa. Kant não concede tanto à música, porém difere aquela percepção do tom [ton] da percepção propriamente musical [musik], assim como empreendido por Rousseau: "Mas no atrativo e no movimento do ânimo, que a música <Musik> produz, a matemática não tem certamente a mínima participação; ela é somente a condição indispensável (conditio sine qua non) daquela proporção das impressões" 31 .

Kant considera que o conteúdo próprio da música encontra-se na transitoriedade da passagem de esquemas de afeto, movimentando nosso ânimo, e não no traço formal da obra.

Para Justi e Giordanetti, a beleza musical ainda poderia ser negociada com o conhecimento científico e em último caso até mesmo com a matemática. Porém, no trecho acima, Kant deixa claro a incapacidade da matemática em participar dos problemas relativos tanto ao gosto como da experiência musical. Quanto a Euler, esse acreditava na capacidade da ciência em demonstrar essa relação.

29 Idem, 15-16

30 ROUSSEAU, J. Ensaio sobre a origem das línguas. Campinas: Editora Unicamp, 1998, p. 189.

31 KANT, I. Crítica da faculdade do juízo, 220. 
A distinção entre o que seja o musical e o que seja o sonoro, herdado de Rousseau, já havia convencido Kant de que o estudo da natureza do som constituía uma investigação distinta daquilo que seria uma análise musical ou do que timidamente se constituía enquanto uma fenomenologia musical. Sendo assim, parece muito implausível que a matemática desempenhe algum papel no argumento kantiano.

Uma observação importante a ser feita está no fato de Kant apenas se inquirir a respeito do som enquanto som [ton], e sobretudo, no fato dele perguntar: "uma cor ou um tom [...] é em si um jogo belo de sensações" ${ }^{32}$ e não simplesmente afirmar.

Tal detalhe é crucial, pois faz desta uma questão do próprio Kant e não de Euler, tendo em vista que para Euler, na música, são ajuizados enquanto belos apenas os intervalos de notas. Ou seja, nunca os sons isolados, mas em dinâmica uns com os outros, e esta é sua metodologia inclusive para o princípio de afinação:

Em seguida abordou o problema da afinação justa dos instrumentos musicais, considerando que o ouvido não julga os sons porque satisfaçam as justas proporções, senão pela percepção agradável e conveniente, de modo que há que centrar a atenção nas sequências de som que resultem harmoniosas. ${ }^{33}$

Contrariamente a Vicente Justi, não vemos qualquer tentativa de Kant em fundamentar a beleza musical matematicamente ${ }^{34}$, este seria o propósito de Euler. Kant já se posicionou contrário a tal fundamento, assim como se posiciona contra as teorias fisiológicas da beleza, como a de Burke ${ }^{35}$. Também discordamos de Justi quando aponta que uma decisão de Kant, em aceitar ou não o som, isolado, como uma beleza em si, acarretaria assim a inclusão ou não da música como uma arte bela, ou mesmo de um compromisso com a teoria de Euler ${ }^{36}$.

Tendo em vista este "mínimo" de decorrências que uma decisão kantiana sobre a beleza do som acarretaria sobre sua teoria da beleza musical, temos que discordar mesmo de Giordanetti, não sobre o fato de Kant não se decidir, pois de fato ele não se decide sobre a questão, mas da ideia que Kant estaria, nesta reflexão, pensando em aderir ou não à teoria de Euler.

Nossa posição é a de que Kant está fazendo uma reflexão própria, que não se apoia na estética de Euler, mas, tão somente, em sua acústica e óptica enquanto estas dissertam sobre eventos vibratórios pertinentes à percepção sensória. Assim, ele se pergunta se um som ou uma cor poderiam por si mesmo ser dotados de beleza. Esta pergunta Euler não se faz. Para Euler o som em si pode ser musical (consonante, dissonante) ou não musical (ruído).

32 Idem, 226

33 VELÁZQUEZ, D.; LONNGI, P. Contribuiciones de Leonhard Euler a la acústica. Miscelânea Matemática: Sociedad Matemática Mexicana, p. 18.

34 JUSTI, V. A música agradável, bela e sublime na terceira Crítica de Kant, p. 99.

35 KANT, I. Crítica da faculdade do juízo,130.

36 JUSTI, V. A música agradável, bela e sublime na terceira Crítica de Kant, p. 100. 
Euler, em sua pequena estética, considerava a beleza como que um desenrolar das proporções matemáticas que se mostram dinamicamente nas proporções dos tons. Porém, o modo como estas proporções desencadeiam a beleza musical estaria para além de seus trabalhos ${ }^{37}$. Sua obra Do verdadeiro caráter da música moderna data de 1764, e Kant, ao publicar a Crítica da faculdade do juízo em 1790, acaba por tentar desautorizar esta pretensão.

Marcando mais uma vez a diferença entre os autores, Euler considera o prazer musical como o resultado de um julgamento acerca dos elementos que o compositor dispõe, e esse julgamento é mais afeito à conjunção psicofísica: "O prazer provém de que imaginemos os pontos de vista e sentimentos do compositor, cuja execução, enquanto a julguemos satisfatória [heureuse], enche a mente de uma agradável satisfação" 38 .

A estética de Euler pretende confluir a música com um fundamento físico/matemático, caráter este que arranca elogios de Bernoulli, e influencia decididamente a obra de Helmholtz. Traz assim um mote de questões musicais muito interessantes, mas que não estão presentes no trabalho de Kant.

Kant deixa de lado qualquer fundamento naturalista, físico, acústico e psicoacústico para a determinação do fenômeno musical, e confere a ele, assim como fez Rousseau, uma autonomia que the é assegurada apenas no âmbito fenomenológico, e que deva encontrar seu fundamento na filosofia transcendental e não nas ciências empíricas. Essa consideração de Kant é bastante importante porque reflete descobertas posteriores da psicologia descritiva, como o conceito de "qualidade de figura" de Ehrenfels, e tantos outros fenômenos que desembocaram nas correntes fenomenológicas do final do século XIX e inicio do XX.

Porém, a fenomenologia de Kant também possui incoerências, uma vez que, sua crítica à transitoriedade e à falta de traços mnemônicos à música e, em seguida, a crítica à aplicação de formas matemáticas que conformem traços mnemônicos, falha bastante em caracterizar o objeto musical. De um lado, sua descrição fenomenológica concede bastante autonomia ao fenômeno musical frente às ciências e ao próprio som, porém, na continuidade de seus comentários, Kant parece se dedicar somente em demonstrar um tipo de simploriedade inerente à fenomenologia musical, que a torna incapaz de cognição e juízo configurando assim um mero jogo de sensações.

37 FISVHER, M. Leonhard Euler et la Musique. REPERES - Revue des Instituts de recherche sur l'enseignement des mathématiques, Nancy, №62, 2006, p.49.

38 EULER apud FISCHER, M. Leonhard Euler et la Musique. REPERES - Revue des Instituts de recherche sur l'enseignement des mathématiques, p. 49. 


\section{A teoria estético-musical da terceira Crítica: a ideia estética musical}

Fora do Hall das belas artes, e ao mesmo tempo, sem qualquer relação matemática ou contiguidade objetiva com o sonoro; não se tratando de uma beleza pura, nem de uma beleza aderente; não portando conceitos; ou ainda, sem expressar um cálculo de percepções sonoras, não resta dúvida de que há apenas um espaço bastante limitado ao fenômeno musical na obra kantiana, a música prefigura um caso muito específico de beleza livre.

Ao mesmo tempo, Kant cita a existência de uma ideia estética muito particular à música, ligada aos esquemas de afetos. Notemos que, diferente das demais artes, a música é a única a ter sua ideia estética esmiuçada e explicitada em uma definição. O que indica que Kant teve uma preocupação especial com a música, a despeito das falhas fenomenológicas que levaram a música a uma qualificação apressada enquanto beleza livre.

Contudo, em um único parágrafo ${ }^{39}$ encontramos uma descrição fenomenológica bastante condizente com a escuta que seria considerada de "vanguarda" no período clássico, sobretudo para sinfonias, condizendo inclusive com relatos que perduram até os dias atuais e são objeto de pesquisa da neurociência ${ }^{40}$. Kant se adiantou bastante às ciências naturais e positivistas ao declarar ser o fenômeno musical algo distinto da soma de sons individuais em padrões matemáticos ou de expectativas baseadas em padrões estatísticos. Kant teve a clarividência em perceber que a música não pode ser descrita deterministicamente enquanto evento biológico, e que a percepção de um momento como de um ponto culminante não é despertado pela injeção de dopamina feita pelo organismo, mas ao contrário, a percepção e compreensão de um ponto culminante, enquanto tal, em uma via de compreensão cognitiva e significativa é que pode possibilitar tal descarga no organismo. Ou seja, não se trata de uma correlação psicofísica direta entre sensação perceptiva (sensibilidade) e reação corporal (prazer), mas na verdade, há uma mediação feita pelo entendimento, uma compreensão que torna o evento uma entidade significável, e

39 KANT, I. Crítica da faculdade do juízo, 219.

40 Estudos como os de Panksepp e Blood-Zatorre demonstram a correlação entre passagens musicais (sobretudo aquelas referentes a um "ponto culminante" do discurso musical) e emoções com fortes componentes corporais, como arrepios cutâneos e arrepios na espinha. Embora estudos desse gênero pretendam descrever processos cognitivos e funções biopsíquicas como a busca por recompensa, pouco se discute o quanto esses trabalhos avançam em suas conclusões abandonando a fenomenologia musical específica daquela experiência. Kant, embora seu modelo não concorra mais na atualidade, se destaca frente a psicologia e neurociência de orientação reducionista diante da pretensão de se compreender a experiência musical, por concorrer com princípios fenomenológicos e preparar uma metodologia mais afeita à música, sem inverter a ordem da compreensão e experiência ao correlato empírico cerebral. Cf. PANKSEPP, J. The Emotional Sources of "Chills" Induced by Music. Music Perception An Interdisciplinary Journal, California, Vol. 13, No. 2, 1995, pp.171-207 e BLOOD, A.; ZATORRE, R. Intensely pleasurable responses to music correlate with activity in brain regions implicated in reward and emotion. National Academy of SciencesPNAS, vol. 98, no. 20, set./2001, pp. 11818-11823. 
portanto, mediando a relação entre sensação perceptiva e sensação emotiva.

Vamos contemplar alguns trechos dessa descrição, e analisar seu componente fenomenológico e teórico: “O seu atrativo, que se deixa comunicar tão universalmente, parece repousar sobre o fato de que cada expressão da linguagem possui no conjunto um som que é adequado ao seu sentido" ${ }^{41}$.

Kant inicia com um comentário acerca da linguagem, mais uma referência ou coincidência ao texto de Rousseau, escrito por volta de 1750, mas que foi editado postumamente em 1781, praticamente dez anos antes da terceira Crítica. 0 texto é Ensaio sobre a origem das línguas:

A melodia, imitando as inflexões da voz, exprime as lamentações, os gritos de dor, ou de alegria, as ameaças, os gemidos. Devem-se-lhes todos os sinais vocais das paixões. Imita as inflexões das línguas e os torneios ligados, em cada idioma, a certos impulsos da alma. ${ }^{42}$

Rousseau acredita que a música faz imitar as inflexões da linguagem; Kant parece apenas entender que há um grau de compartilhamento, não conferindo poder afigurativo e imitativo como faz Rousseau, novamente, uma distinção que só é possível ser feita em nível fenomenológico e que Kant procede com muita cautela. Kant acredita que, quando desligado de seu conteúdo linguístico original, o som musical traça uma sucessão de formas de afeto que se remetem a sentenças, sem contudo representar nada além da forma do afeto. Seria como uma "linguagem universal das sensações”43. A qualificação da música enquanto aconceitual é plenamente justificada quanto a esse aspecto, pois não seria possível imputar à música o conteúdo ou conceito de um sentimento, ou qualquer caráter imitativo. Novamente a fenomenologia kantiana parece bastante coerente e supera as posições de Rousseau.

A descrição do evento de um ponto culminante e de uma ideia associada à percepção musical é certamente inédita na literatura musical, e configura-se como uma percepção típica das obras em forma sonata:

pelo fato de aquelas ideias estéticas não serem nenhum conceito e pensamento determinado, a forma da composição destas sensações (melodia e harmonia) serve somente de forma de uma linguagem para, mediante uma disposição proporcionada das mesmas (a qual pode ser submetida matematicamente a certas regras, porque nos sons ela assenta sobre a relação do número das vibrações de ar no mesmo tempo, na medida em que os sons são ligados simultânea ou também sucessivamente), expressar a ideia de um todo coerente de uma indizível profusão de pensamentos, conforme a um certo tema que constitui na peça o afeto dominante ${ }^{44}$.

41 KANT, I. Crítica da faculdade do juízo, 219

42 ROUSSEAU, J. Ensaio sobre a origem das línguas, 190.

43 KANT, I. Crítica da faculdade do juízo, 219.

44 Idem, ibidem. 
Temos aqui uma abundância de noções que são associadas de uma forma bastante atípica, mas que podem ser discernidas. As noções aconceituais aparecem nos termos: sensação, indizível profusão e afeto. As noções conceituais aparecem nos termos: forma (melodia e harmonia), linguagem, proporção matemática, ideia e tema. Contudo, elas parecem estar todas reunidas sob o conceito de "ideia de um todo coerente". 0 que é uma confluência atípica para a caracterização pregressa da música feita por Kant.

A primeira observação feita versa que a composição da forma musical, que pode ser estrategicamente composta com recurso matemático, criando uma verdadeira linguagem com base objetiva e conceitual, pode ser usada para alocar aquilo que é da esfera puramente sensória, sem que essa estrutura transmita um conteúdo conceitual ao sensível. Está assente no som a capacidade em traçar formalmente um afeto, como a montagem de um esquema da imaginação, e é nesse sentido que Kant falará do tema musical não enquanto uma célula de percepção lógica, mas enquanto aquilo que constitui o arranjo do esquema de um afeto, ou seja, um elemento ainda aconceitual.

Assim, o conteúdo que está a correr e fluir pela peça é ele integralmente sensível, notem: o tema musical é ele mesmo apenas uma marca abstrata de um esquema, e o que está verdadeiramente a acometer o ouvinte em sua percepção não é nada mais do que uma indizível profusão de sensações. Contudo, Kant vislumbra a possibilidade dessa profusão se converter em um fluxo de pensamentos. Embora desconsidere qualquer determinação ou quantidade junto à percepção musical, essa descrição que mantém já é um salto demasiado grande para o que viemos caracterizando enquanto música para Kant.

Para o filósofo, qualquer som modulado suscita sensações em nível corporal, e, nisso a que a neurociência pôde de fato contribuir demonstrando uma correlação entre a escuta musical e a ativação de diversas áreas motoras e regiões de recompensa, Kant somou também essa correlação a uma outra que supera inclusive a teoria dos afetos, que já vinha vinculando som, afetos e sensações no corpo, relações que sempre estiveram no campo de interesse da ciência moderna.

O salto dado por Kant acontece em virtude de sua maior preocupação em manter sua descrição fenomenológica a mais acurada possível, e investiga assim os sentimentos de clímax, que também inundam nosso corpo enquanto contemplamos uma música. Kant passa a descrever não mais o comportamento visto em terceira pessoa, mas a fenomenologia em primeira pessoa de uma experiência musical. Isso que "de fora" parece um clímax é vivenciado pelo ouvinte de uma maneira muito diferente, inclusive, de modo surpreendentemente diferente, de uma mera sensação. Essa mudança de perspectiva possibilitou a Kant introduzir a ideia de um "todo coerente" pertencente à experiência de uma escuta musical. 
Do ponto de vista do ouvinte, a ideia de um todo coerente é despertada pela confluência entre uma forma musical movida por cálculos que não são conscientes, mas que sugerem modelos e unificações, ao mesmo tempo em que vivenciamos uma torrente de sensações pelo tempo. Será a capacidade que temos em compreender a torrente enquanto uma manifestação de elementos que se harmonizam, ou estão em via de se mostrarem unificados por um princípio único, que desperta essa precisa ideia, de que estamos diante de um "todo coerente". A música despertaria, assim, não apenas uma ideia estética, mas uma ideia estética bastante determinada, que coincide inclusive com a etimologia da palavra synfonia: ação daquilo que soa (Phone) junto, unificado (Sym).

Kant parece ter adicionado um material precioso a sua teoria estética, não fosse o fato desse processo de uma ideia estética musical não ser o fim dessa experiência, mas ter contiguidade em mais um novo processo, que em grande medida, invalida toda a produção intelectual que vimos ocorrer na ideia estética, uma vez que esse estado típico da percepção de pontos culminantes retornaria imediatamente e realimentaria a sensação corpórea, não se mantendo enquanto livre jogo da imaginação com o entendimento ${ }^{45}$. Embora vejamos que traços importantes das belas artes e mesmo de juízos de gosto puro poderiam dar um amparo teórico a essa descrição, são eles todos cancelados e remetidos a um estado corporal de gozo. Curiosamente, a principal chave interpretativa do fenômeno musical pela neurociência vem sendo o "mecanismo" da obtenção de prazer e da fuga da dor.

Se observamos como a reação dos músicos da música clássica no final do século XVIII corria em paralelo aos textos estéticos em voga, demonstrando uma falta de correlação entre as disciplinas teóricas e as novas expressões musicais, podemos dizer que já no século XVIII pouco se justificava a acentuação do mero gozo dos sentidos dado como conteúdo da atividade musical, mesmo para Kant. Assim, nos chama atenção que até o século XXI, o discurso sobre a base sensível da escuta musical ainda perpetue antigos fundamentos.

Pegando o gancho desse comentário, podemos indicar que escapou a Kant uma observação mais atenta ao papel do tema musical em uma obra. Ao mesmo tempo, faltou a Kant descrever com o devido pormenor o que seriam os esquemas de afeto e como são despertados e vivenciados em uma experiência musical.

Na composição musical, o tema é o substrato da compreensibilidade da obra, e a ideia a qual Kant lança mão, de um "todo coerente" faz parte da estruturação musical clássica desde os primeiros compassos. 0 tema se vê variado, desenvolvido e destrinchado sob esta profusão que é inicialmente harmônico-melódica, mas que Kant diz ser então substituída por uma profusão de afetos, uma substituição que não foi justificada de modo algum. Outro fato incomum está em Kant qualificar o fluxo

45 Idem, 225 
de sons enquanto transitórios e incompreensíveis, aconceituais, mas que passam a estar aptos a uma ideia estética quando são encapsulados pelos esquemas de afetos. Sendo esses afetos puramente formais, sem qualquer conteúdo e igualmente transitórios. Ou seja, não há conceito, substancialmente imitativo ou objetivo, que esteja servindo de lastro para a ideia estética. E o que garante esse lastro é na verdade um arranjo matemático dos componentes sonoros, justamente esse elemento que Kant julgava ser um recurso que causava tão somente enfado, recurso rejeitado por Kant enquanto parte do fenômeno musical, mas que aparece aqui enquanto componente essencial da formalização da peça musical.

Afinal, o que faz a forma sonata senão justamente traçar um percurso melódico e harmônico que busca um equilíbrio entre a unidade temática em meio às profusões e variações que se imprimem em seu prosseguir temporal? Não seria a escuta musical clássica, da forma sonata, por si mesma, o percurso de uma tensão entre um "todo coerente" e uma aparente multiplicidade disforme?

A única ideia estética que a música é capaz de evocar não se encontraria em uma simetria tal, ou analogia, com o próprio modelo do conhecimento? Ou seja, a tarefa de, em meio a uma imediata desorganização e profusão da natureza, encontrar uma regra universal, um todo coerente? Sabemos que Kant conduz tal ideia novamente para uma sensação corporal, e que esta não aparece como uma experiência consistente da reflexão. Mas qual o sentido em se determinar a produção musical da música clássica e os gênios de sua composição como meros produtores de deleite sonoro em uma degustação de prazeres amenos? As razões de Kant não parecem plenamente acessíveis, ou, há realmente uma confluência de problemas teóricos com problemas fenomenológicos, os quais Kant não soube tratar amplamente.

Não podemos deixar de notar que o conceito de "todo coerente" compõe um núcleo original da reflexão kantiana, e de um modo ou de outro aponta para um componente intelectual, mesmo que negado, ou denegado na contiguidade da experiência musical. Ao rejeitar alguns princípios basilares da teoria dos afetos, e ao mesmo tempo rechaçar tanto a música instrumental como as futuras pretensões idealistas da música absoluta, Kant se coloca em um lugar sui generis.

\section{Compreender a música e compreender Kant}

A tese do livre jogo das sensações que a música desempenharia é única e original de Kant. As razões de Kant para chegar a esse arranjo perpassam por descrições de cunho fenomenológico e sua teoria transcendental do juízo de gosto. Contudo, várias características fenomenológicas destacadas por Kant entram em conflito e por vezes se contradizem, seja entre si ou com a teoria que busca resguarda-las. De um lado, a percepção musical não seria nada mais do que a percepção de sensações qualitativas puras, sem qualquer determinação, mas ao mesmo tempo, a percepção 
musical consegue se configurar como um fenômeno que ultrapassa a mera percepção pontual de sons. Aceitando a constatação de Rousseau, é rejeitada a matemática enquanto condição de possibilidade assente na percepção de tipo musical, mas, ao mesmo tempo, diz ser a matemática um elemento central na evocação da ideia estética.

O século XVIII foi uma era de efervescência nesta área e muitos nomes se destacam entre a ciência e a estética musical: Rameau, Euler, Rousseau, Kant, D’Alembert, Triest, Michaelis, Reinhard, etc. Se há pouca unidade entre estes trabalhos, podemos também dizer que a vinda do século XIX não ajudou em nada, acrescentando ainda mais inquéritos, incluindo novos discursos metafísicos ao debate musical. De toda forma, as questões do século XVIII constituem a porta de entrada da estética musical moderna e seu acúmulo vislumbrou uma pretensão de unificação no século XIX com o trabalho de Eduard Hanslick em Do belo musical.

Em sentido negativo, e inadvertidamente, Kant estimulou uma resposta por parte dos especialistas em música, e dali em diante maiores feitos teóricos tomaram forma, na constituição de um discurso mais coerente com a autonomia da arte musical. Johann K. F. Triest elabora e publica em 1801 (oito anos após a publicação da segunda edição da Crítica da faculdade do juízo) na revista de crítica musical Allgemeine Musikalische Zeitung, o termo música pura, marcando assim o advento, no meio intelectual, de uma supremacia da música instrumental.

Enfim, estaria correta a assertiva de Wheterston que diz ser a obra kantiana pessoal e implausível?

Afora certa implausibilidade que acompanha todo discurso teórico-hipotético, Kant se notabilizara por adjurar uma estética tradicional, ainda vinculada a um papel subsidiário da música, aderindo a um perfil perceptivo-fenomenológico em grande medida aquém da então música instrumental. Ao mesmo tempo, sua observação sobre a ideia de "um todo coerente" abre a possibilidade de pensarmos a música enquanto portadora de alguma espécie de cognição e objetividade, elementos importantíssimos para o trabalho de Hanslick. Nossa opinião é de que Kant fornece aquilo que promete, um quadro bastante especulativo e experimental e não há porque reprovar seu ímpeto, sobretudo quando traz aquela marca possível apenas a um grande pesquisador, em trazer material que exceda a sua própria tolerância. Em termos de sua pessoalidade, como comentamos em outro momento, parece que Kant carrega mais traços da coletividade onde habitava do que apenas um traço individualizante.

0 que se percebe na continuação daquilo que foram os estudos em estética musical é que os trabalhos passaram a ser mais frutíferos quanto mais foram analisados separadamente os atributos cognitivos, fenomenológicos e fisiológicos, mas ainda assim uma unidade e contiguidade desses estudos, que parece ainda longe de ser atingida, tem nessas especulações kantianas ao menos um impulso convergente. 


\section{Referências}

BLOOD, A.; ZATORRE, R. Intensely pleasurable responses to music correlate with activity in brain regions implicated in reward and emotion. National Academy of Sciences-PNAS, vol. 98, no. 20, set./2001, pp. 11818-11823.

DUARTE, R. Belo, sublime e Kant. Belo Horizonte: Editora UFMG, 1998.

A aconceptualidade da música em Kant e suas ressonâncias: Hegel e Adorno. In: MARQUES, U. Kant e a Música. São Paulo: Editora Barcarolla, 2010, pp. 281-299.

FISCHER, M. Leonhard Euler et la Musique. REPERES-Revue des Instituts de recherche sur l'enseignement des mathématiques, Nancy, N62, 2006, pp. 42-56. http: // www.univ-irem.fr/reperes/articles/62_article_428.pdf. Acesso em 08/12/2014.

JUSTI, V. A música agradável, bela e sublime na terceira Crítica de Kant. In: MARQUES, U. Kant e a Música. São Paulo: Editora Barcarolla, 2010, pp. 93-111.

KANT, I. Crítica da Faculdade do juízo. $2^{\text {a }}$ edição. Rio de janeiro: Forense Universitária, 1993.

HANSLICK, E. Do belo musical. Lisboa: Edições 70, 2002.

MARQUES, J. Harmonia e melodia na segunda analogia da experiência de Kant. In: MARQUES, U. Kant e a Música. São Paulo: Editora Barcarolla, 2010, pp. 129-141.

MARTINS, C. O belo e a música. In: MARQUES, U. Kant e a Música. São Paulo: Editora Barcarolla, 2010, pp. 75-91.

NACHMANOWICZ, R. Lógica e música: conceitualidade musical a partir da filosofia de Kant e Hanslick. Belo Horizonte: Editora Relicário, 2014.

PANKSEPP, J. The Emotional Sources of “Chills" Induced by Music. Music Perception An Interdisciplinary Journal, California, Vol. 13, No. 2, 1995, pp.171-207.

ROUSSEAU, J. Ensaio sobre a origem das línguas. Campinas: Editora da Unicamp, 1998.

VELÁZQUEZ, D.; LONNGI, P. Contribuiciones de Leonhard Euler a la acústica. Miscelânea Matemática: Sociedad Matemática Mexicana, San Andrés Totoltepec, n. 46, Mayo/2008, pp.1-25. http://www.miscelaneamatematica.org/Misc46/ Lonngi.pdf. Acesso em 08/04/2014.

VIDEIRA, M. A recepção da crítica do juízo na literatura musical do início do séc. XIX. In: MARQUES, U. Kant e a música. São Paulo: Editora Barcarolla, 2010, pp. 181209.

WEATHERSTON, M. Kant Assessment of music in the critique of judgment. British journal of Aesthetics, Oxford, Vol. 36, n. 1. 1996, pp. 56-65. 